\title{
Characteristics of the fibroplasia and collagen expression in the abdominal wall after implant of the polypropylene mesh and polypropylene/polyglecaprone mesh in rats $^{1}$
}

\author{
Maria de Lourdes Pessole Biondo-Simões ${ }^{\text {I }}$ Camila Gomes de Morais ${ }^{I I}$, Anna Flávia Zonato Tocchio ${ }^{\text {II }}$, Renata Augusta de \\ Miranda", Paula Almeida Pamponet Moura", Kelly Colla ${ }^{\text {II }}$, Rogério Ribeiro Robes ${ }^{\text {III, }}$, Sérgio Ossamu Ioshii ${ }^{\mathrm{IV}}$, Flávio Daniel \\ Saavedra Tomasich ${ }^{\mathrm{V}}$
}

DOI: http://dx.doi.org/10.1590/S0102-865020160050000001

IPhD, Associate Professor, Department of Surgery, Universidade Federal do Paraná (UFPR), Brazil. Intellectual and design of the study, analysis of data, manuscript writing, final approval the version to be published.

IIGraduate student, Scientific Initiation Program, UFPR, Curitiba-PR, Brazil. Technical procedures.

IIIMaster, Full Professor, Department of Anesthesiology, Faculty of Veterinary Medicine, UFPR, Curitiba-PR, Brazil. Analgesia and post-operatory care, manuscript writing.

${ }^{\text {IV }} \mathrm{PhD}$, Associate Professor, Division of Pathology, Pontifícia Universidade Católica do Paraná (PUCPR), and UFPR, Curitiba-PR, Brazil. Critical revision.

${ }^{\mathrm{v}} \mathrm{PhD}$, Head, Division of Experimental Surgery, Department of Surgery, UFPR, Curitiba-PR, Brazil. English language, critical revision.

\section{ABSTRACT}

PURPOSE: To compare fibroplasia and the resistance of the abdominal wall when polypropylene meshes and polypropylene/ poliglecaprone are used.

METHODS: Seventy-seven male Wistar rats were divided into three groups: Control Group (for resistance); Group E (polypropylene mesh); and Group U (polypropylene/poliglecaprone mesh). The animals in Groups E and U had a standard muscular and aponeurotic defect, with integral peritoneum, and correction with the mesh. Measurements were taken 4, 7, 14, 28 and 56 days after surgery. The resistance, and collagen density were studied.

RESULTS: Resistance on the $56^{\text {th }}$ day was similar in both meshes. The gain in resistance described an ascending curve for the polypropylene mesh and was irregular in the case of the polypropylene/poliglecaprone. Fibroplasia showed a gain in type I and type III collagen in both groups $(p<0.001)$. Collagen III stabilized in the $14^{\text {th }}$ day and collagen I continued to ascend.

CONCLUSIONS: The gain in resistance of the polypropylene mesh is regular and ascending, whereas the polypropylene/poliglecaprone is not regular. The final resistance of both meshes is similar; the collagen density increases over time, and show the same inflammatory potential.

Key words: Surgical Mesh. Hernia, Ventral. Wound Healing. Collagen. Rats. 


\section{Introduction}

An incisional hernia, ventral hernia or eventration consists of protruding viscera through an abnormal opening in the abdominal wall following a surgical procedure ${ }^{1}$.

According to an American analysis, one in ten patients submitted to a laparotomy develops an incisional hernia ${ }^{2-4}$. It is estimated that approximately $50 \%$ of incisional hernias occur in the first two years following a surgery, and $74 \%$ in the first three years $^{5-7}$.

An incisional hernia forms due to defective healing following a laparotomy, the mechanism of which is of a multi factor nature. The collagen deposition and the environment of the healing of the wound are among the main mechanisms involved ${ }^{8}$.

Following a median laparotomy, the rectus muscles maintain their origin and insertion, but the insertion of the lateral muscles is lost. Anatomically, the linea alba consists of a tendon which, when cut, induces muscular alterations of the abdominal wall $^{8}$. When the insertion of the tendon is dislocated from the large muscles that support the abdomen and consequently their retraction, incisional hernias worsen, especially those of the median line. This is a result of atrophy, fatty degeneration and fibrosis of the lateral muscles, factors that hinder the reinsertion of the reinsertion of the tendon in the supporting muscle ${ }^{8}$.

Repairs using tension-free techniques are currently recommended. The introduction of the polypropylene mesh by Usher et al. ${ }^{9}$ was a great step towards definitive treatment of hernias and led to a significant reduction in recurrence rates.

Random studies have shown that $31 \%$ to $55 \%$ of treatments without the use of meshes result in a hernia relapse ${ }^{10}$. However, treatments with a mesh result in a relapse in $16 \%$ to $24 \%$ of cases $^{10-13}$.

An ideal mesh is one that has good resistance to traction, has no carcinogenic potential, is chemically inert (no potential for infection or delaying healing), is capable of developing an inflammatory response to the material and does not cause rejection. It is also important that it does no cause an allergy or hypersensitivity, has a low cost, enables sterilization, has the capacity to resist mechanical stress and can be incorporated by the host ${ }^{14,15}$.

The most frequently used prostheses are inorganic. The most widely used is polypropylene ${ }^{16}$. Its intra peritoneal use is associated with adverse effects such as adhesion, chronic pain, bowel obstruction and fistulas ${ }^{17-19}$.

Fibroplasia or wound healing is characterized by a harmonious and coordinated sequence of cellular and molecular events that interact to promote repair and reconstruction of the damaged tissue, the extension of which depends on local inflammatory activity ${ }^{14,20}$. It is a requirement for the reconstruction of a mechanically stable abdominal wall ${ }^{17}$.

The polypropylene mesh is surrounded by dense fibrotic material, the consequence of the local reaction to the wound and the presence of the mesh. The strengthening of the abdominal wall with this mesh is the result of the resistance of the mesh itself and the surrounding fibrosis, and its biointegration results from the inflammatory infiltrate and connective tissue synthesis ${ }^{21}$.

The combination of non-absorbable and absorbable material, such as the combination of polypropylene and poliglecaprone or even polyglactine could modify the inflammatory pattern and favor the deposition of connective material around the fibers $^{3,21}$.

In the first part of this study we studied the inflammatory reaction $^{22}$. The aim of this study was to compare the use of a nonabsorbable mesh of polypropylene and a partially absorbable mesh made of polypropylene and poliglecaprone filaments, evaluating the resistance of the abdominal wall and collagen expression both qualitatively and quantitatively.

\section{Methods}

The study was evaluated by the Ethics Committee on the Use of Animals in Biological Sciences, Universidade Federal do Paraná (UFPR), allotted process number 23075.038578/201211, approved on 30/11/2012 - R.O. 11/2012, as number 659 and in compliance with Federal Law 11.794, which establishes the procedures for the scientific use of animals.

Seventy-seven male Wistar rats (Rattus norvegicus albinus, Rodentia mammalia) aged 140 days and weighing $422.54 \pm 64.19 \mathrm{~g}$ from the Central Vivarium of UFPR were used. They were housed in groups of five in polypropylene boxes of appropriate dimensions for the species. The dark/light cycle was 12 hours, the temperature was $20 \pm 2^{\circ} \mathrm{C}$ and the humidity was that of the environment. They had free access to water and standard commercial food. The sample was divided into three groups at random: the control group ( $\mathrm{GC}, \mathrm{n}=7)$, the polypropylene group $(\mathrm{GE}, \mathrm{n}=35)$ and the polypropylene/poliglecaprone group (GU, $\mathrm{n}=35)$. GE and GU were subdivided into five groups of seven in accordance with the time of evaluation $(4,7,14,28$ and 56 days) following surgery.

For GE a $180 \mu\left(\right.$ Marlex $^{\circledR}$, Cirúrgica Brasil) polypropylene mesh was used. This mesh is non-absorbable and is of high density, with average pores of $0.8 \mathrm{~mm}$ and an estimated weight of $100 \mathrm{~g} / \mathrm{m}^{2}$. 
For GU, a mixed mesh of polypropylene and poliglecaprone was used (Ultrapro $^{\circledR}$, Johnson \& Johnson International, C/O European Logistic Centre, Belgium). This is a low density, partly absorbable mesh with pores greater than $3.0 \mathrm{~mm}$ and an estimated weight of $28 \mathrm{~g} / \mathrm{m}^{2}$.

Under general anesthetic, assisted by a veterinary surgeon, a median incision of approximately four centimeters was made in the skin and subcutaneous mesh. A muscularaponeurotic fragment with a diameter of $1.5 \mathrm{~cm}$ was removed from the abdominal wall. The parietal peritoneum was preserved intact. The defect was corrected by inserting the mesh, according to the group to which each animal belonged, in a pre-peritoneal situation. The mesh was attached with eight separate stitches using polypropylene monofilament thread 4.0, followed by a skin synthesis, with the application of a continuous suture of nylon monofilament 4.0 .

Having recovered from the anesthetic and the administration of an intramuscular analgesic (dipyrone $10 \mathrm{mg} / \mathrm{kg}$ ), the animals were returned to their boxes, where they remained until the day of their euthanasia, under the same environmental and feeding conditions they had experienced prior to the surgery.

Euthanasia was performed using a lethal dose of intraperitoneal thionembutal $(120 \mathrm{mg} / \mathrm{kg})$, in accordance with the guidelines of Resolution 1000 of the Brazilian Federal Council of Veterinary medicine. For the necropsy, a new laparotomy was performed. A macroscopic analysis evaluated the presence of secretions and the integrity or otherwise of the corrected region. A segment was removed from the abdominal wall measuring $6.0 \mathrm{~cm}$ in width and $4.0 \mathrm{~cm}$ in length with the implanted mesh and divided transversally. The cranial half was retained in a physiological solution and enabled an immediate evaluation of the resistance and the caudal half was set in formaldehyde $10 \%$ for the histological study.

The resistance of the abdominal wall was analyzed using an EMIC DL-500 MF ${ }^{\circledR}$ extensometer and MTest EMIC ${ }^{\circledR}$ software. The values of resistance for GC, GE and GU were obtained. The resistance of the walls of the control group was obtained without intervention and this served to compare the gain in resistance of the corrected walls with that of normal walls.

The process continued with the histological technique. To identify the collagen, Picrosirius Red staining was used. The images were captured by a Sony CCD101 camera transmitted to a Trinitron Sony ${ }^{\circledR}$ color monitor, frozen and digitalized using an oculus $\mathrm{TCX}^{\circledR}$. The images were analyzed using Image-Plus ${ }^{\circledR}$ 4.5 for Windows ${ }^{\circledR}$ from MediaCybernetics on a microcomputer. In each cut, five fields enlarged 400 times were analyzed. The presence of collagen I and collagen III was analyzed.
For the statistical analysis, the median, standard deviation and minimum and maximum values were used. To evaluate these tests between the groups at different times, the parametric MannWhitney test was used, and for the intra-group evaluation the Kruskal-Wallis was used. To analyze frequency, Fisher's exact test was used. A $\mathrm{p} \leq 0.05$ or $5 \%$ was established as the level for rejection the null hypothesis. The program used for the statistical analysis was Statsoft, Inc (2008). Statistica (data analysis software system), version 8.0.

\section{Results}

There was a loss of information on six animals due to postoperative occurrences. Thirty-four animals of the GE group remained and thirty from GU.

No macroscopic abscesses were found and the mesh syntheses were intact at the time of evaluation. There were no intracavity adhesions.

The median resistance of the walls in GC was $2.42 \pm 0.41$ $\mathrm{N}$, varying between 1.65 and $2.82 \mathrm{~N}$. On the fourth day there was a median resistance of $\mathrm{GU}$ corresponded to $66.53 \%$ for the wall of $\mathrm{GC}$ and that of GE to $69.83 \%$ of the resistance of GC $(\mathrm{p}=0.931)$. Both groups showed a gain in resistance over time (Figure 1). On the $56^{\text {th }}$ day, the median resistance of the GU walls reached a level of $93.40 \%$, compared with the resistance of GC; the walls of GE were $92.15 \%$ of the GC value $(\mathrm{p}=0.876)$. The gain in resistance was more regular in GE and more irregular in GU.

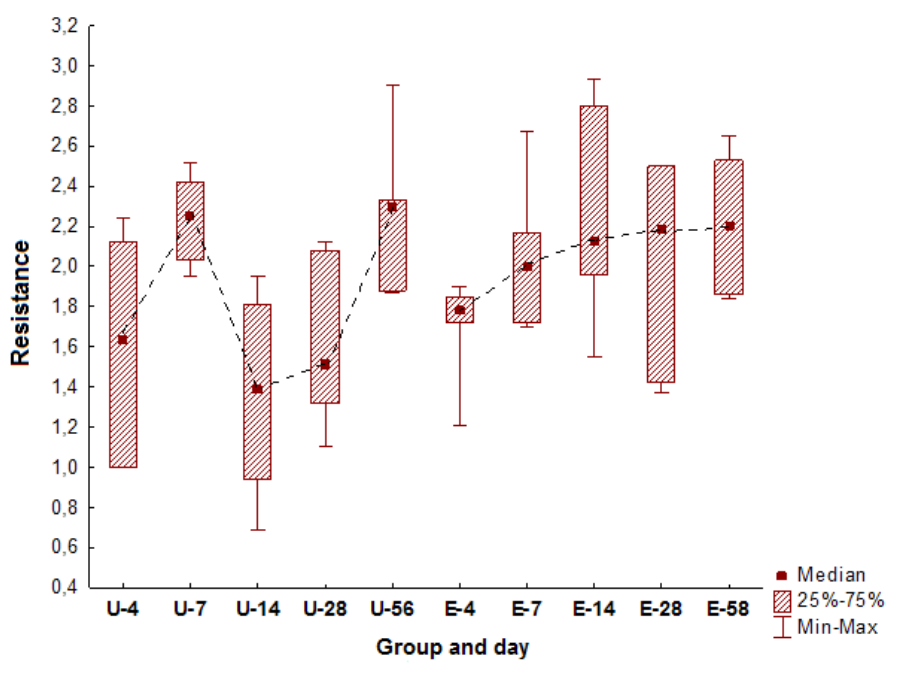

FIGURE 1 - Medians, quartiles, minimums and maximums in GE and $\mathrm{GU}$ at the five times under study.

The median total collagen in five fields showed a similar gradual gain of this protein in both groups (Figure 2). In the initial 
evaluations, more type III collagen was found. This quantity of collagen grew significantly until the $14^{\text {th }}$ day, when the gain curve stabilized. The type I collagen, found in minimal quantities at first, showed a growth in gain throughout the observation period in both groups $(\mathrm{p}<0.001)$. In the early stages of the process, the septa showed little collagen, which was disordered and predominantly type III. As time passed, the septa became thicker and there was an increase in type I collagen. At first, the disposition of the collagen fibers was disordered, gaining in order and thickness, especially when evaluated on the $56^{\text {th }}$ day.

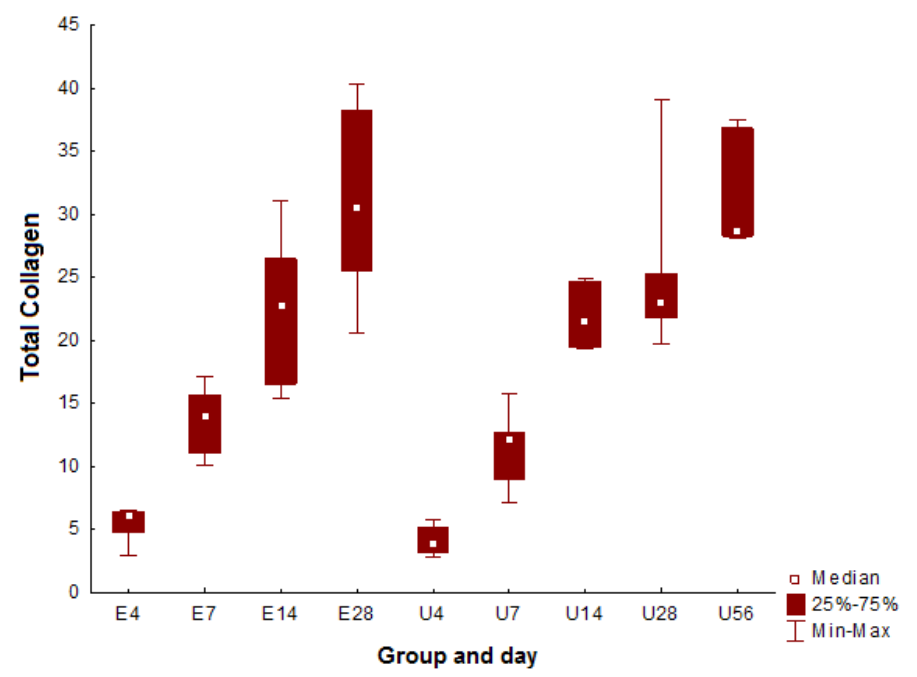

FIGURE 2 - Graph showing the collagen gain in groups GE and GU at the five times under study.

NOTE: Comparative Mann-Whitney Test between the groups

4th day: $p=0.093$; 7 th day: $p=0.394 ; 14$ th day: $p=0.628 ; 28$ th day: $p=0.699 ; 56$ th day: $\mathrm{p}=0.202$

\section{Discussion}

The treatment of incisional hernias, especially in large proportions, is a challenge to any surgeon. Many biological and synthetic materials have been used with high, medium and low weights and with macro, medium and micro pores without any consensus being reached.

Although there have been descriptions of possible infection, hematomas, seromas and screen encapsulation, many authors have not reported such complications ${ }^{15,19,23}$. In the sample described in this study, no such situation was observed.

The resistance of a wound may be influenced by a set of factors including interactions between cells, the extracellular matrix and cytokines. The classic tissue reaction to the placing of the prosthesis is characterized by an intense inflammatory response that results in disordered deposition of collagen around the prosthesis and in the interstice of its fibers. The fibroblast reaction can cause mesh encapsulation. During the second week of healing, the fibroblasts in the wound perform the function of myofibroblasts, contributing to the definitive organization of the connective tissue and the contraction of the wound, factors that influence the final resistance of the wound ${ }^{24}$.

The complete incorporation of the mesh is an important requirement for obtaining a good attachment ${ }^{15}$. The degree of infiltration of cells such as macrophages, fibroblasts, collagen and new vessels, depends on the size of the pores of the prosthesis, and the healing process requires an adequate pore size between 75 and $100 \mu \mathrm{m}^{25}$. Strengthening the abdominal wall with the use of a polypropylene mesh is achieved by increasing resistance to traction and is the result of the presence of the mesh and the fibrotic reaction induced by the mesh with the infiltration of inflammatory cells and the deposition of the tissue favoring the biointegration of the mesh ${ }^{15,26}$.

Non-absorbable synthetic meshes based on polymers (polypropylene, polyester) provide adequate supply of inflammatory cells and fibrosis, and are useful in maintaining the tensile resistance of the tissue ${ }^{27}$. This enables the prosthesis to attach to the tissues that surround it.

Regarding weight, meshes with a low molecular weight (under $40 \mathrm{~g} / \mathrm{m}^{2}$ ) have better biocompatibility and this reduces complaints of postoperative pain and discomfort. These prostheses tend to be macroporous and composed of polymers such as polypropylene interwoven with absorbable material such as polyglactine or poliglecaprone. The combination of absorbable and non-absorbable materials can reduce complaints. Macro pores and the partial reabsorption of the mesh would enable the accumulation of fat instead of fibrotic material between the areas of granuloma formulation, allowing the tissue greater elasticity. However, some studies have shown that due to these factors, there has been an increase in the rate of relapse of hernias corrected with this type of $\operatorname{mesh}^{28}$.

Utrabo et al. ${ }^{19}$, in a study similar to the present study, showed that walls corrected with polypropylene and polypropylene/ poliglecaprone, evaluated after 30 days, had similar resistance $(p=0.4702)$. However, evaluation after sixty days showed greater resistance in the walls corrected with polypropylene/ poliglecaprone $(\mathrm{p}=0.0046)$.

Altmel et $a .^{29}$ evaluated after 7 and 21 days and observed that the walls gained resistance but the polypropylene/ poliglecaprone apparently gained less resistance. 
In the present study, evaluations were made after 4, 7, 14, 28 and 56 days. On the fourth day, the resistance was compatible with $66.53 \%$ of the normal wall when repaired with polypropylene/poliglecaprone and $69.83 \%$ when repaired with polypropylene ( $\mathrm{p}=0.931$ ). After 56 days, the resistance of both groups had attained just over $90 \%$ of the resistance of a normal wall, with no significant difference between them.

There is no consensus regarding gain in resistance with the polypropylene/poliglecaprone mesh. In the constitution of this mesh there is an absorbable substance and over time it could lead the walls corrected by it to be less resistant. According to information from the manufacturer and Junge et $a l .{ }^{30}$, this part of the mesh would be reabsorbed in up to 84 days. Perhaps longer term observation could answer these questions. However, it should be remembered that the biological cycle of a rat is faster than that of a human and, thus, 56 days could be adequate time.

An analysis of the resistance curve showed that the walls corrected with polypropylene saw a progressive gain, stabilizing on the $14^{\text {th }}$ day, while the curve for polypropylene/poliglecaprone showed a gain until the seventh day and on the fourteenth day an important loss was observed $(\mathrm{p}=0.008)$, with the gains returning on the $28^{\text {th }}$ day and becoming similar to the polypropylene group on the $56^{\text {th }}$ day. In other words, the polypropylene mesh had a regular gain curve whereas the polypropylene/poliglecaprone did not. This irregularity may be due to the inflammatory reaction and even the absorbable part of the mesh, although the study by Junge et $a l .{ }^{30}$ describes the first histological signs of the reabsorption of the poliglecaprone filaments after 56 days. However, these authors did not measure resistance. It should be considered that the inflammatory process would influence resistance.

Median total collagen density in the experiment showed a similar gradual gain of this protein in both groups over time, with the values always a little higher, but not significantly so, in GE. Utrabo et al. ${ }^{19}$ claimed, in qualitative terms, that polypropylene meshes led to the formation of more fibrous tissue. The study by Junge et al. ${ }^{30}$ showed that there was no difference in collagen levels when a polypropylene or polypropylene/poliglecaprone mesh was used.

\section{Conclusions}

The resistance offered by the polypropylene mesh has a regular and ascending gain as the process evolves, while that of the polypropylene/poliglecaprone is not regular. The final resistance of both meshes is similar. The collagen density increases over time and is similar for both meshes.

\section{References}

1. de Castro Brás LE, Shurey S, Sibbons PD. Evaluation of crosslinked and non-crosslinked biologic prostheses for abdominal hernia repair. Hernia. 2012;16(1):77-89. doi: 10.1007/s10029-011-0859-0.

2. Schreinemacher MH, Emans PJ, Gijbels MJ, Greve JW, Beets GL, Bouvy ND. Degradation of mesh coatings and intraperitoneal adhesion formation in an experimental model. $\mathrm{Br} \mathrm{J}$ Surg. 2009;96(3):305-13. doi: 10.3109/13814788.2015.1055466.

3. Cassar K, Munro A. Surgical treatment of incisional hernia. Br J Surg. 2002;89(5):534-45. PMID: 11972542.

4. Dunn R, Lyman MD, Edelman PG, Campbell PK. Evaluation of the SprayGel adhesion barrier in the rat cecum abrasion and rabbit uterine horn adhesion models. Fertil Steril. 2001;75(2):411-6. PMID: 11172849.

5. Anthony T, Bergen PC, Kim LT, Henderson M, Fahey T, Rege RV, Turnage RH. Factors affecting recurrence following incisional herniorrhaphy. World J Surg. 2000;24(1):95-100. PMID: 10594211.

6. Rudmik LR, Schieman C, Dixon E, Debru E. Laparoscopic incisional hernia repair: a review of the literature. Hernia. 2006;10(2):110-9. PMID: 16453075.

7. Scalco PPC, Gonçalves da Costa R, Lontra MB, Jotz GP, Marques FB, Cavazzola LT. Comparação entre a tela de submucosa intestinal suína acelular (Surgisis ${ }^{\circledR}$ ) e a tela polipropileno (Marlex ${ }^{\circledR}$ ) na formação de aderências peritoneais: estudo experimental em ratos. Rev AMRIGS. 2008;52(3):197-203.

8. Dubay DA, Choi W, Uubanchek MG, Wang X, Adamson B, Dennis RG, Kuzon W M, Franz MG. Incisional herniation induces decreased abdominal wall compliance via oblique muscle atrophy and fibrosis. Ann Surg. 2007;245(1):140-6. doi: 10.1097/01. sla.0000251267.11012.85.

9. Usher FC. Hernia repair with knitted polypropylene mesh. Surg Gynecol Obstet. 1963;117(2):239-40.

10. den Hartog D, Dur AH, Tuinebreijer WE, Kreis RW. Open surgical procedures for incisional hernias. Cochrane Database Syst Rev. 2008;(3):CD006438. doi: 10.1002/14651858.CD006438.pub2.

11. Luijendijk RW, Hop WCJ, van den Tol MP, de Lange DC, Braaksma MM, Ijzermans JN, Boelhouwer RU, de Vries BC, Salu MK, Wereldsma JC, Bruijninckx CM, Jeekel J A. A comparison of suture repair with mesh repair for incisional hernia. N Engl J Med. 2000;343(6):392-8. PMID: 10933738.

12. Burger JW, Luijendijk RW, Hop WC, Halm JÁ, Verdaasdonk EG, Jeekel J. Long-term follow-up of a randomized controlled trial of suture versus mesh repair of incisional hernia. Ann Surg. 2004;240(4):578-83. doi: 10.1097/01.sla.0000141193.08524.e7.

13. Flum DR, Horvath K, Koepsell T. Have outcomes of incisional hérnia repair improved with time? A population-based analysis. Ann Surg. 2003;237(1):129-35. PMID: 12496540.

14. Jin J, Voskerician G, Hunter AS, McGee MF, Cavazzola LT, Schomish S, Harth K, Rosen MJ. Human peritoneal membrane controls adhesion formation and host tissue response following intra-abdominal placement in a porcine model. J Surg Res. 2009;156(2):297-304. doi: 10.1016/j.jss.2009.04.010.

15. Vaz M, Krebs RK, Trindade EM, Trindade MRM. Fibroplasia after polypropilene mesh implantation for abdominal wall hérnia repair in rats. Acta Cir Bras. 2009;24(1):19-25. doi: 10.1590/S010286502009000100005.

16. Doctor HG. Evaluation of various prosthetic materials and newer meshes for hernia repairs. J Minin Access Surg. 2006;2(3):110-6. PMID: 21187889.

17. Bringman S, Conze J, Cuccurullo D, Deprest J, Junge K, Klosterhalfen B, Parra-Davila E, Ramshaw B, Schumpelick V. Hernia repair: the search for ideal meshes. Hernia. 2010;14(1):81-7. doi: 10.1007/s10029-009-0587-x. 
18. Gaertner WB, Bonsack ME, Delaney JP. Visceral adhesions to hernia prostheses. Hernia. 2010;14(4):375-81. doi: 10.007/S1002910-0659-y.

19. Utrabo CA, Czeczko NG, Busato CR, Montemor-Netto MR, Malafaia O, Dietz UA. Comparative study between polypropylene and polypropylene/poliglecaprone meshes used in the correction of abdominal wall defect in rats. Acta Cir Bras. 2012;27(4):300-5. doi: 10.1590/S0102-86502012000400004.

20. Hunt TK, Hopf HW. Wound healing and wound infection. What surgeons and anesthesiologists can do. Surg Clin North Am. 1997;77(3):587-606. PMID: 9194882.

21. Klinge U, Klosterhalfen B, Müller M, Schumpelick V. Foreign body reaction to meshes used for the repair of abdominal wall hernias. Eur J Surg. 1999;165(7):665-73. PMID: 10452261.

22. Biondo-Simões MLP, Moura PA P, Colla K, Tocchio AFZ, Morais CG, Miranda RA, Robes RR, Ioshii SO. Inflammatory reaction and tensile strength of the abdominal wall after an implant of polypropylene mesh and polypropylene/poliglecaprone mesh for abdominal wall defect treatment in rats. Acta Cir Bras. 2014;29 Suppl 1:45-51. PMID: 25185056.

23. Pereira-Lucena CG,Artigiani-Neto R, Lopes-Filho GJ, Frazao CVG, Goldenberg A, Matos D, Linhares MM. Experimental study comparing meshes made of polypropilene, polypropilene + polyglactin and polypropilene + titanium: nflammatory cytokines, histological changes and morphometric analysis of collagen. Hernia. 2010;14(3):299-304. doi: 10.1007/S10029-009-0621-z.

24. Rossi LF, Ramos RR, Kestering DM, Soldi MS, Ely JB, D'Acampora AJ. Tensile strength study of the abdominal wall following laparotomy synthesis using three types of surgical wires in Wistar rats. Acta Cir Bras. 2008;23(1):73-7. doi: 10.1590/S010286502008000100012.

25. Brown CN, Finch JG. Which mesh for hernia repair? Ann R Coll Engl. 2010;92(4):272-8. doi: 10.1308/003588410X1266419207629 6.

26. Leroy JL, Mutter D, Forgione A, Inoue H, Vix M, Bailey C, Marescaux J. The new 4DDome prosthesis: an original light and partially absorbable composite mesh for hernia repair. Hernia. 2006;10(5):401-8. PMID: 16969587.
27. Araújo URF, Czezcko NG, Deallarmi A, Hemoviski FE, Araújo HVCP. The choice of the mesh composition to use in the intraperitoneal position in the surgical repair of abdominal wall defects. ABCD Arq Bras Cir Dig. 2010;23(2):118-21. doi: 10.1590/ S0102-67202010000200012.

28. Weyhe D, Schmitz I, Belyaev O, Grabs R, Müller KM, Uhl W, Zumtobel V. Experimental comparison of monofile light and heavy polypropylene meshes: less weight does not mean less biological response. World J Surg. 2006;30(8):1586-91. PMID: 16855805.

29. Altmel Y, Öztürk E, Özkaya G, Akyildiz EÜ,Ulcay Y, Özgüç H. The effect of a chitosan coating on the adhesive potential and tensile strength of polypropylene meshes. Hernia. 2012;16(6):709-14. doi: 10.1007/S10029-012-0950-1.

30. Junge K, Rosch R, Krones CJ, Klinge U, Mertens PR, Lynen P, Schumpelick V, Klosterhalfen B. Influence, of polyglecaprone 25 (Monocryl) supplementation on the biocompatibility of a polypropylene mesh for hernia repair. Hernia. 2005;9(3):212-7. PMID: 15703859.

\section{Correspondence:}

Maria de Lourdes Pessole Biondo-Simões

Rua Ari José Valle, 459

82030-025 Curitiba - PR Brasil

Tel./Fax: (55 41)3297-4359

malubiondo@gmail.com

Received: Jan 11, 2016

Review: Mar 14, 2016

Accepted: Apr 12, 2016

Conflict of interest: none

Financial source: none

${ }^{1}$ Research performed at Division of Experimental Surgery, Universidade Federal do Paraná (UFPR), Brazil. 